\title{
Pesquisa e Prática Clínica: Construindo Articulações Teóricas
}

\author{
Research and Clinical Practice: Constructing Theoretical Links
}

\author{
Terezinha Féres-Carneiro* \\ Pontifícia Universidade Católica do Rio de Janeiro, Rio de Janeiro, Brasil
}

\begin{abstract}
Resumo
Neste texto, apresentado na Aula Inaugural, proferida no Programa de Pós-graduação em Psicologia do Desenvolvimento da Universidade Federal do Rio Grande do Sul (UFRGS) em 10/03/08, discutem-se as articulações construídas pela autora a partir de sua inserção na academia e na prática clínica. A história de um percurso de 36 anos, como docente-pesquisadora e como psicóloga clínica, é relatada, ressaltando o modo indissociável de conceber tais funções. Neste relato, são explicitadas e discutidas as possibilidades de articular diferentes enfoques teórico-técnicos na clínica. Uma tríplice chave de leitura, que considere o intra-psíquico, o interacional e o social, é proposta no atendimento a famílias e casais.
\end{abstract}

Palavras-chave: Pesquisa; prática clínica; articulações teóricas.

\begin{abstract}
In this text, which was presented at the Inaugural Lecture from the Graduate Program of Developmental Psychology at Universidade Federal do Rio Grande do Sul (UFRGS) on March 03, 2008, are discussed the links constructed by this author in the academic work as well as in the clinical practice. The history of a 36-year journey as both a professor-researcher and also as a clinical psychologist is reported here, with emphasis on the inseparable way of conceiving such functions. In this account it is explained and discussed the possibilities of articulating different theoretical-technical approaches in the clinic. The proposal for family and couple psychological assistance is a tripartite key of reading which takes into consideration the intra-psychological, the interactional and the social aspects of the aforementioned ones.
\end{abstract}

Keywords: Research; clinical practice; theoretical links.

Considero que o convite que me foi feito, para estar aqui hoje, tem muito a ver com os vínculos que me unem ao Programa, quando ainda da sua gestação. Minha história pessoal é marcada por uma forte vocação para a "madrinhagem". Tenho muitos afilhados e afilhadas com idades que vão dos 6 aos 46 anos. E, além destas pessoinhas maravilhosas, cujo crescimento acompanho de perto, vários Programas de Pós-graduação do Brasil (quase todos os da área da Psicologia Clínica) com os quais colaborei, dando consultoria na elaboração dos Projetos de implantação ou de reformulação, acabaram ficando também neste lugar de afilhados, Programas pelos quais torço muito e cujo crescimento acompanho com alegria. Alguns deles, até me chamam de madrinha.

Esta é um pouco, também, a minha história com o Programa de Pós-graduação em Psicologia do Desenvolvimento da Universidade Federal do Rio Grande do Sul (UFRGS). História que teve início no ano de 1987. Lá se vão 21 anos e ainda tenho viva, na memória, aquela vinda a Porto Alegre. Os professores Cláudio Hutz e William Gomes tinham me solicitado uma consultoria para avaliar o Projeto de

\footnotetext{
* Endereço para correspondência: Pontifícia Universidade Católica do Rio de Janeiro, Centro de Teologia e Ciências Humanas, Departamento de Psicologia, Rua Marquês de São Vicente, 225, Gávea, Rio de Janeiro, RJ, 22453-900. Tel.: (21) 3527 1186; Fax: (21) 35271187
}

implantação da Pós-graduação stricto sensu, e gostariam também de realizar comigo uma entrevista.

Fazia muito calor em Porto Alegre. William vestia uma bermuda e carregava um daqueles gravadores enormes, que acho que já nem existem mais, e caminhávamos pelo Campus em busca de uma sala onde iríamos trabalhar. $\mathrm{O}$ clima era de muito entusiasmo e os dois jovens doutores queriam me perguntar muitas coisas, mas esperavam, sobretudo, que eu avaliasse o projeto de implantação do Mestrado, com atenção especial para a sua estrutura curricular, e que desvendasse, para eles, o que era quase um mistério à época: como articular a prática clínica com a atividade acadêmica? Esta segunda parte da nossa conversa foi gravada e publicada com o título "A prática clínica e o trabalho acadêmico: Uma entrevista com a psicóloga Terezinha Féres Carneiro", na recém-criada Revista Psicologia: Reflexão e Crítica (Gomes \& Hutz, 1987).

No ano seguinte, em 1988, foi implantado o Mestrado em Psicologia do Desenvolvimento da UFRGS. Diz um sábio provérbio chinês que "a maior alegria do mestre é ver o discípulo ultrapassá-lo”. E, esta alegria de ter podido, em 1987, agregar um pouco da minha experiência em Pós-graduação ao Projeto do Programa que estava por nascer, e ver, hoje, este Curso ultrapassar Programas tradicionais - inclusive o Programa do qual faço parte, o primeiro a ser criado no Brasil, em 1966 - e ser avaliado com a nota 
7, nota máxima do sistema de avaliação da Coordenação de Aperfeiçoamento de Pessoal de Nível Superior (CAPES), é, para mim, fonte de indescritível alegria. Da alegria que inunda o mestre ao ver o discípulo ultrapassá-lo.

Gostaria, então, que a minha fala nesta Aula Inaugural fosse, em primeiro lugar, uma fala de comemoração e uma fala de felicitação ao corpo docente, ao corpo discente e ao corpo administrativo, pelo rigoroso e brilhante trabalho realizado nestes 20 anos, que coloca o Mestrado e o Doutorado em Psicologia do Desenvolvimento desta casa como o melhor (junto com outros dois) Programa de Pós-Graduação em Psicologia do Brasil. Gostaria de parabenizar, também, os editores da Revista Psicologia: Reflexão e Críti$c a$, pelo incansável trabalho realizado nestes 22 anos de existência, ao longo dos quais tem sido um dos mais importantes veículos de publicação da produção em psicologia no país, sendo uma das duas únicas revistas avaliadas como Internacional A, no Qualis da área. Parabéns a vocês, professores, alunos e funcionários pelo trabalho realizado e pelos justos resultados alcançados!

Antes de falar sobre meu percurso como clínica-pesquisadora, e sobre algumas das articulações que marcaram este percurso, queria dizer que a tendência a promover articulações está presente, desde muito cedo, na minha história. Sabemos que não é por acaso que escolhemos uma profissão, como também não é por acaso que escolhemos o modo como vamos exercê-la. Desde muito jovem, entre os familiares, no grupo de amigos, entre os colegas do colégio, eu era quase sempre solicitada para ouvir histórias de relacionamentos, solucionar conflitos, mediar diferenças, conciliar posições. Chegada a hora do vestibular, não tive dúvidas: sabia que queria cursar Psicologia na Pontifícia Universidade Católica do Rio de Janeiro (PUC-Rio). Da escola fundamental à universidade, fui sempre escolhida como representante da turma, e no exercício desta função, quase sempre, minha principal tarefa era a de articular diferenças.

A dicotomia entre pesquisa e prática profissional em Psicologia e as possibilidades de articulação entres estas duas atividades, que tanto intrigavam os jovens doutores da UFRGS que me entrevistaram em 1987, foram discutidas por vários autores da área. O professor César Piccinini, em trabalho publicado nas Coletâneas da ANPEPP (Piccinini, 1996), discutindo a relação entre o pesquisador e o profissional em Psicologia, apresenta, a partir de estudos de alguns pesquisadores americanos, as várias fases do desenvolvimento das relações entre a pesquisa e a profissão em psicologia nos Estados Unidos. O autor ressalta a necessidade de se desenvolver uma nova concepção de mutualidade entre ciência e profissão em psicologia, e uma postura, na universidade, que promova a integração entre pesquisa e prática profissional desde os primeiros anos do curso de graduação. Enfatiza, também, que a interdependência entre pesquisa e prática deve ser baseada no pluralismo metodológico.

O debate sobre a relação entre a formação do profissional e a formação do pesquisador contou com acaloradas discussões em congressos e reuniões científicas da área, no país. Nestas ocasiões, não foi sem entusiasmo e muita convicção que, sempre, marquei uma posição firmemente contrária àquelas que argumentavam que a Psicologia Clínica não teria, na pós-graduação stricto-sensu, o mesmo lugar das outras áreas do saber psicológico e que seu espaço por excelência seria o da especialização.

No artigo intitulado "Academia e profissão em Psicologia Clínica: Da relação possível à relação desejável" (Féres-Carneiro, 1993), defendo a necessidade de se estreitarem, cada vez mais, as relações entre a academia e a profissão de psicólogo clínico. Ressalto a responsabilidade da universidade na crítica e na produção do conhecimento em Psicologia, em qualquer de suas áreas de aplicação. A prática teorizada precisa ter seu lugar na pós-graduação stricto-sensu, para garantir a formação do docente-pesquisador nas áreas profissionais da Psicologia. Como ensinar e pesquisar nestas áreas sem ser profissional? Como criticar e produzir o conhecimento em Psicologia Clínica sem ser clínico? Como fazê-lo fora da universidade, fora dos Cursos de Mestrado e Doutorado?

A articulação da clínica com a pesquisa sempre esteve presente desde o início da minha formação: no terceiro ano do curso de graduação em Psicologia, fui contratada como monitora da disciplina Técnicas de Exame Psicológico e iniciei meu estágio em diagnóstico psicológico. Ficava encantada com a possibilidade de estar atendendo pacientes em diagnóstico e estar participando do ensino e da pesquisa numa disciplina de avaliação psicológica. No final da graduação, surgiu meu interesse teórico-técnico pela família, pelo diagnóstico e pela terapia familiar. Cursei a Especialização em Terapia Familiar e Arte-Diagnóstico Familiar, ministrada pela Dra. Hanna Kwiatkowska, da George Washington University, à época, professora visitante da PUC-Rio.

A preocupação em criticar e construir o conhecimento, na clínica de família e casal, que me acompanhou ao longo da Especialização, permaneceu no Curso de Mestrado. Constatei que, a maioria dos métodos de avaliação familiar existentes requeria um equipamento nem sempre encontrado nas clínicas brasileiras, que todas as técnicas tinham sido construídas no exterior e que nenhum estudo sistemático sobre elas, com população brasileira, tinha sido realizado. Decidi, então, no trabalho de dissertação de mestrado (Féres-Carneiro, 1975), elaborar o primeiro método de avaliação das relações familiares construído no Brasil.

O novo método de avaliação clínica precisava ser validado. No ano seguinte, encaminhei ao Conselho Nacional de Desenvolvimento Científico e Tecnológico (CNPq) uma solicitação de Bolsa de Pesquisa para realizar o estudo de validação. Fui então contemplada em 1977, quando o CNPq ainda concedia bolsas a pesquisadores não doutores, com uma bolsa de pesquisa no nível III A, para desenvolver o projeto de validação da Entrevista Familiar Estruturada. Nesta investigação, todavia, o objetivo inicial de validar o método não foi atingido, tendo em vista alguns problemas metodológicos e dificuldades encontradas pelas famílias de nível sócio-econômico mais baixo, na compreensão de 
algumas das tarefas, inicialmente formuladas a partir do atendimento a famílias de segmentos médios da população. Esta pesquisa passou a ter, então, o objetivo de introduzir as modificações necessárias para que a Entrevista Familiar Estruturada pudesse ser aplicada a famílias de diferentes segmentos sócio-econômicos da população.

A partir da concessão da referida bolsa de pesquisa, permaneci - sempre com a minha preocupação em articular pesquisa e clínica - no sistema de bolsas do CNPq, até a presente data. São 31 anos ininterruptos como bolsista de pesquisa no CNPq. Segundo informação deste órgão, tratase da segunda bolsa mais antiga em vigência no sistema.

Uma vez realizadas as modificações que esta investigação propôs, permanecia a necessidade de validação da Entrevista Familiar Estruturada. Com este objetivo, desenvolvi a pesquisa do Doutorado, realizado na Pontifícia Universidade Católica de São Paulo - PUC-SP (Féres-Carneiro, 1981). Foram estudadas 18 famílias de diferentes segmentos sócio-econômicos, pertencentes a dois grupos contrastantes: famílias consideradas facilitadoras do desenvolvimento emocional de seus membros e famílias consideradas dificultadoras de tal desenvolvimento. $\mathrm{O}$ coeficiente geral de fidedignidade do avaliador encontrado foi de 0,85 , o que pode ser considerado um bom nível de consistência entre os dois avaliadores do estudo. A validade simultânea, calculada através da correlação entre as avaliações concedidas pelos juízes e a medida de critério, apresentou um coeficiente geral de 0,93. A partir deste estudo, a Entrevista Familiar Estruturada foi divulgada como um método clínico capaz de discriminar uma dinâmica familiar dificultadora de saúde emocional, de uma dinâmica familiar facilitadora de saúde emocional (Féres-Carneiro, 1983). O método se mantém, até hoje, como o único no Brasil construído, com esse objetivo.

Recentemente, a Casa do Psicólogo se interessou por publicá-lo como teste psicológico, e o mesmo foi submetido à análise no Conselho Federal de Psicologia (CFP), tendo recebido parecer favorável em 31/03/2005 (FéresCarneiro, 2006). A Entrevista Familiar Estruturada tem sido muito utilizada na clínica, sobretudo, em clínicasescola nos processos de avaliação e de terapia de família. Seu uso também tem sido grande em pesquisas de Mestrado e de Doutorado na área de família e casal no país.

Depois de dez anos de pesquisas realizadas na clínica, sobre a estrutura e a dinâmica da família, e sobre diagnóstico e terapia familiar, no início dos anos 80 , meus interesses voltaram-se para uma análise específica do casal parental e do casal conjugal no grupo familiar.

Desenvolvi algumas pesquisas que discutem a relação entre dificuldades emocionais apresentadas por crianças e conflitos existentes nas interações estabelecidas por seus pais. Dentre estes trabalhos, destaco a investigação sobre sintomas infantis e terapia de casal, onde estudo, num período de dois anos, oito casais em terapia (Féres-Carneiro, 1980). A análise dos dados clínicos mostrou que embora cinco casais tenham buscado terapia para seus filhos que apresentavam problemas, tais dificuldades eram conseqüências das perturbações e dos conflitos existentes na relação do casal. Em apenas dois, dos oito casos estudados, os filhos precisaram ser vistos em sessões de avaliação familiar e, em apenas um caso, um filho precisou ser encaminhado para uma psicoterapia individual. Concluo que, na maioria das vezes, os problemas apresentados pelas crianças encontram suas raízes na relação dos pais e que, quase sempre, é suficiente uma intervenção com o casal para que haja remissão dos sintomas apresentados pelos filhos. Esta é uma posição que continuo defendendo, cada vez mais, com maior convicção.

Da clínica para o social e do social para a clínica, continuei ampliando meus interesses no estudo da relação conjugal, desenvolvendo várias pesquisas sobre casamento, separação, recasamento e terapia de casal. Nestas investigações, privilegio, por um lado, o estudo das dimensões de aliança e sexualidade e, por outro, o estudo das tensões existentes entre individualidade e conjugalidade. Costumo dizer que todo o fascínio - e toda dificuldade - de ser casal, reside no fato de o casal encerrar, ao mesmo tempo, na sua dinâmica, duas individualidades e uma conjugalidade. Como ser um, sendo dois? Como ser dois, sendo um?

No atendimento a casais de primeiro casamento e casais recasados, observei algumas das diferenças significativas que se estabelecem entre o primeiro casamento e os casamentos subseqüentes, em relação às dimensões de aliança e sexualidade, e às dimensões de individualidade e conjugalidade. As questões, em geral, começam a me inquietar na clínica e, a partir dela, muitas vezes, desenvolvo pesquisas com a população geral.

Em uma investigação com sujeitos não clínicos (FéresCarneiro, 1987), estudei dez casais de primeiro casamento e dez casais de casamentos subseqüentes, com idades entre 25 e 45 anos, com filhos, e tempo de vida conjugal entre 3 e 13 anos. Ficou evidenciado que, em relação à escolha conjugal, no grupo de primeiro casamento, a aliança assume um papel mais significativo que a sexualidade, enquanto esta é mais relevante para os recasados. Em ambos os grupos, o relacionamento sexual é considerado muito importante para o casal, mas a sexualidade aparece de forma mais personalizada e criativa entre os recasados, para os quais as demandas e expectativas em relação à atividade sexual são maiores. Tais resultados me permitiram voltar para a clínica de casais com um olhar enriquecido em relação às questões que envolvem o casamento e o recasamento.

Em meados da década de 80, desenvolvi um grande interesse pelos autores franceses de orientação psicanalítica no trabalho com famílias e casais. Assim, em 1988, realizei um Pós-doutorado, desenvolvendo atividades na Itália e na França. Escolhi trabalhar com a Dra. Ana Maria Nicollò, à época, do Instituto de Terapia Familiar de Roma, e com o Dr. Jean Lemaire, da Universidade de Paris 5, Sorbonne, e da Associação de Psicanálise e Sistema Familiar, por serem psicanalistas que propõem uma articulação das abordagens sistêmicas com as abordagens psicanalíticas no trabalho com famílias e casais.

Com minha formação como terapeuta de família e casal marcada, em alguns momentos, por influências predominantemente sistêmicas, e, em outros, por influências pre- 
dominantemente psicanalíticas, tenho criticado a rigidez dos puristas destas duas abordagens e tenho defendido a possibilidade de articular diferentes enfoques em terapia de família e de casal. Em algumas publicações, dentre as quais destaco (Féres-Carneiro, 1996), discuto esta questão, concordando com autores como Lemaire (1984) e Nicollò (1988). O que vemos nas duas abordagens, é que, de um modo geral, na perspectiva sistêmica, prevalece uma preocupação com o aqui e agora, com a interação e a busca de modificá-la, o que leva a uma desatenção em relação aos processos psíquicos subjacentes. Enquanto na perspectiva psicanalítica, há uma preocupação com a história e os processos inconscientes que estão na origem da disfunção familiar. A proposta de articulação considera que estas duas concepções teóricas, e as práticas delas decorrentes, não podem deixar de considerar que a família e o casal são grupos organizados, auto-regulados, com uma linguagem própria, regras próprias de funcionamento e mitos próprios.

Quando defendo a possibilidade de articulação, considero, como Jean Lemaire, que é preciso uma tríplice chave de leitura, no trabalho clínico com famílias e casais, que passe pelo intrapsíquico, pelo interacional e pelo social. Para este autor, o fato, por exemplo, de o terapeuta de casal compreender psicanaliticamente os fenômenos inconscientes das identificações projetivas que estão na base da colusão narcísica do casal, não deve impossibilitá-lo de lançar mão de desenvolvimentos teórico-técnicos das teorias sistêmicas. Ele pode, ao mesmo tempo, trabalhar sobre a comunicação, as expressões paradoxais, os duplos-vínculos, sem estar impedido de levar em conta processos arcaicos inconscientes, que estão em jogo desde o estabelecimento da relação amorosa (Lemaire, 1984).

Outra autora, que possui posição semelhante, é Ana Maria Nicollò que fala de um "rigor elástico", isto é, de uma atitude que requer, nas disciplinas psicológicas, a intuição, a subjetividade do observador que são insubstituíveis para o conhecimento, quando discute a possibilidade de articulação dos enfoques sistêmicos e psicanalíticos em terapia de família e casal (Nicollò, 1988).

Sempre lançando mão desta possibilidade, dei continuidade às investigações sobre relação amorosa, casamento, separação e terapia de casal, a partir do atendimento clínico, ao longo de três anos a 16 casais da classe média carioca, estudando as relações existentes entre a manifestação da individualidade e da conjugalidade, os tipos de escolha amorosa e a manutenção ou a ruptura do casamento (Féres-Carneiro, 1995).

Os resultados desta pesquisa mostraram que, dos casais estudados, 10 se mantiveram casados e 6 se separaram. A ruptura ou não do casamento, teve uma relação menos significativa com a presença maior ou menor da individualidade e da conjugalidade na interação e com os tipos predominantes de escolha amorosa, estando relacionada, mais significativamente, com a maneira como tais dimensões puderam-se transformar e como, dentro de cada tipo de escolha amorosa, o casal, ao longo do processo terapêutico, foi capaz de efetuar mudanças no jogo conjunto que envolvia seus membros.
No início da década de 90, uma nova demanda surgiu na minha prática de terapeuta de casal: casais homossexuais procurando ajuda para resolverem suas dificuldades e seus conflitos interacionais. Comecei a observar, nestes atendimentos, algumas semelhanças e diferenças na vivência da relação amorosa, na heterossexualidade e na homossexualidade. Com algumas questões levantadas na clínica, dirigi-me à população geral, para tentar estudar de forma mais ampla estes dois tipos de conjugalidade.

Realizei uma investigação com 240 homens e mulheres heterossexuais, e com 180 homens e mulheres homossexuais dos segmentos médios da população carioca, de diferentes faixas etárias. Os resultados referentes à escolha amorosa foram publicados em (Féres-Carneiro, 1997), e mostram que homens e mulheres heterossexuais valorizam as mesmas qualidades em seus parceiros, ou seja, fidelidade, integridade, carinho e paixão. Tais qualidades são igualmente valorizadas pelas mulheres homossexuais, enquanto os homens homossexuais tendem a enfatizar a importância da atração física e da capacidade erótica de seus parceiros. Resultados que confirmam dados da literatura (Fry \& MacRae, 1981; Heilborn, 1993). Dentre outras constatações deste estudo, verificou-se também que o nível de exigência em relação à escolha do(a) parceiro(a) é muito alto nas mulheres no grupo heterossexual, enquanto no grupo homossexual, a maior exigência é demonstrada pelos homens.

Os resultados referentes à interação conjugal foram publicados em (Féres-Carneiro, 1999). Constatou-se que o relacionamento sexual foi considerado muito importante tanto para os heterossexuais como para os homossexuais. Em relação à frequiência das relações sexuais, os homens e mulheres heterossexuais e as mulheres homossexuais não quantificam as relações, afirmando que a freqüência depende de cada casal. Todavia, a maior parte dos homens homossexuais falaram de uma frequiência desejável, que variou de 3 a 5 vezes por semana. Em relação à fidelidade, a maioria dos sujeitos de ambos os grupos consideraramna como de fundamental importância na relação amorosa, rejeitando a possibilidade de sexo fora do relacionamento. Entretanto, dentre os homossexuais, em torno de um terço das respostas, tanto dos homens como das mulheres, indicaram a alternativa de sexo fora da relação, quer como estímulo para esta, quer como uma possibilidade colocada pela própria definição do relacionamento. No discurso dos homens homossexuais foi possível também perceber uma diferença entre fidelidade amorosa e fidelidade sexual. Para estes sujeitos, a infidelidade sexual não é necessariamente uma traição, enquanto a infidelidade amorosa é sempre considerada uma traição Os resultados obtidos possibilitaram que, de volta à clínica de casais, a escuta em relação a estes diferentes tipos de conjugalidade fosse mais contextualizada. Da clínica para a pesquisa, da pesquisa para a clínica, podemos ir tecendo articulações que promovem a crítica e a construção do conhecimento e que enriquecem nossa escuta e nossa intervenção terapêutica.

Dando continuidade à minha atividade de pesquisa, o projeto seguinte, intitulado "Casamento, separação e tera- 
pia de casal: Estudos sobre a construção e a dissolução do laço conjugal na contemporaneidade", foi desdobrado em três subprojetos desenvolvidos com as camadas médias da população carioca. O primeiro deles, "Casamento contemporâneo: Construção da identidade conjugal", teve seus resultados publicados em (Féres-Carneiro, 2001). Este estudo, realizado com 16 homens e 16 mulheres, de diferentes faixas etárias, casados legalmente, ou não, há mais de 3 anos, com filhos deste casamento, teve como objetivo investigar a construção da identidade conjugal, a vivência da conjugalidade e da individualidade na manutenção do casamento contemporâneo. Em relação à concepção de casamento, tanto os homens como as mulheres ressaltaram a importância da individualidade na vida a dois, ao mesmo tempo em que enfatizaram a importância do compartilhar e dividir. Todavia, somente as mulheres explicitaram as dificuldades decorrentes do conflito individualidade/conjugalidade na vivência da relação conjugal.

Confirmando dados brasileiros de pesquisas anteriores (Féres-Carneiro, 1997; Magalhães, 1993), os homens definiram casamento como "constituição de família" e as mulheres como "relação amorosa". Enquanto os homens ressaltaram a importância da atividade sexual na relação conjugal, as mulheres valorizaram a qualidade e não a frequência das relações sexuais. Em relação à influência da conjugalidade sobre a subjetividade, os homens se perceberam mais tranquiilos após o casamento, enquanto as mulheres, mais seguras e tolerantes. Ainda confirmando resultados de outros estudos (Féres-Carneiro, 1987; Jablonski, 1998), constatou-se que os homens estão mais acomodados na relação conjugal e não demonstram necessidades de fazerem mudanças, enquanto as mulheres estão mais inquietas, ressaltando o desejo de buscar transformações que possam melhorar a vivência da conjugalidade.

O segundo subprojeto, intitulado "Separação conjugal e a construção das identidades individuais" investigou como homens e mulheres vivenciam o processo de dissolução do casamento e buscam construir suas identidades individuais, após a separação. Foi realizada uma pesquisa de campo com 16 homens e 16 mulheres, de duas faixas etárias (25-35 anos e 45-55 anos), separados legalmente, ou não, do primeiro casamento e que ainda não estavam recasados. Os resultados desta investigação foram divulgados em (Féres-Carneiro, 2003a). Não foram encontradas diferenças relevantes nos dois grupos etários estudados. Entretanto, as atitudes e sentimentos de homens e mulheres contrastaram em muitas situações. Delinearam-se, com clareza, um desejo e uma decisão de separação, predominantemente, femininos; o que não significa que a intensidade da dor, vivenciada neste processo, por homens e mulheres, seja diferente. Homens sentindo-se, sobretudo, frustrados e fracassados, e mulheres vivenciando, principalmente, mágoa e solidão, todos eles experimentam um profundo sentimento de dor no processo de ruptura da relação conjugal. Quando homens e mulheres apontam a infidelidade masculina como uma das causas da separação, ao mesmo tempo em que estão ressaltando que a traição masculina é mais tolerada, culturalmente, do que a feminina, estão tam- bém explici-tando uma reação maior das mulheres que, traídas, desejam a separação conjugal. À medida em que as mulheres conquistaram, nas últimas décadas, mais espaços no mercado de trabalho, elas também se expuseram mais a traírem seus cônjuges, ao mesmo tempo em que se tornaram mais exigentes na relação amorosa.

O terceiro subprojeto intitulado "Casamento, separação e terapia de casal", foi desenvolvido no setting clínico, e estudou 18 casais, casados legalmente ou não, atendidos em terapia de casal, ao longo de três anos, cuja demanda continha, como um dos temas, a questão da manutenção ou da ruptura do casamento. Os resultados deste estudo estão publicados em (Féres-Carneiro, 2003b). Dos 18 casais atendidos, 7 se separaram, 7 se mantiveram casados e 4 se separaram e, depois de certo tempo, voltaram a se casar e retornaram à terapia de casal.

De um modo geral, tanto nos casos em que houve ruptura do laço conjugal como naqueles em que não houve, os homens mostraram uma vivência mais negativa da solidão e uma maior dificuldade de ficarem sós, que as mulheres. Em relação à fusão/diferenciação, observou-se a tendência a uma certa fusionalidade tanto no grupo dos casais que se mantiveram casados, como naqueles dos que se separaram e dos que se recasaram. A intensidade com que a fusionalidade estava presente na relação do casal permitia a maior ou menor promoção de saúde emocional na dinâmica conjugal. A maior parte dos casais estudados puderam se beneficiar do processo terapêutico, reduzindo os espaços de fusão e ampliando aqueles da diferenciação.

Quanto à manutenção/dissolução do laço conjugal, constatou-se, em todos os casais, uma grande valorização do casamento, apesar da ambivalência que experimentavam em relação à sua manutenção, ou não, presente na demanda inicial de psicoterapia de todos os casos estudados. Homens e mulheres valorizaram igualmente a manutenção do casamento, embora o discurso feminino tenha enfatizado mais aspectos relacionados à relação conjugal, e o masculino, além destes, tenha explicitado também aspectos relativos à relação com os filhos. Dos 11 casos em que houve ruptura do casamento, em apenas três, prevaleceu no discurso masculino a ênfase no desejo de separação. Em todos os outros casos, foram as mulheres que manifestaram, com mais intensidade, o desejo de se separarem, e apresentaram alternativas para o processo de dissolução do laço conjugal.

Este dado está presente nos resultados de quase todas as pesquisas que temos realizado sobre separação, assim como nos casos que tenho atendido na clínica, nos últimos 36 anos: em geral, os homens só manifestam o desejo de separação quando já estão envolvidos com outra pessoa. Costumo relacionar este resultado referente à demanda predominantemente feminina de separação conjugal, com o modo como homens e mulheres concebem o casamento. Como já mencionei, constatou-se, em pesquisas anteriores, que os homens, em geral, definem casamento como constituição de família, e as mulheres como relação amorosa. Assim, para as mulheres, quando a relação amorosa não vai bem, a separação parece mais inevitável do que para os homens, 
cuja concepção de casamento está mais associada à família. Além disto, vimos também que os homens têm mais dificuldade que as mulheres de ficar sós, o que pode leválos a querer se separar, sobretudo, quando já estão vinculados a outras pessoas.

Podemos ver no desenvolvimento destes três subprojetos, como a intervenção terapêutica pode beneficiar-se dos resultados de pesquisas realizadas com a população não clínica, ao mesmo tempo em que as questões suscitadas na clínica inspiram a formulação de pesquisas com a população geral, que enriquecem a crítica e a produção do conhecimento. É importante não esquecer, também, que o exercício da clínica envolve uma atitude permanente de pesquisa.

O projeto de pesquisa recentemente concluído, intitulado "Conjugalidade dos pais e projeto de vida dos filhos frente ao laço conjugal", teve como objetivo principal estudar as relações existentes entre o casamento dos pais, tal como percebido e vivenciado pelos filhos, e o lugar do laço conjugal no projeto de vida destes. Para atingir este objetivo, a investigação foi desenvolvida em duas etapas, utilizando para isto uma metodologia mista. Na primeira etapa, foi realizada uma pesquisa de levantamento, com 236 jovens solteiros (129 homens e 107 mulheres), das camadas médias da população, com idades entre 19 e 30 anos, que teve como objetivo investigar a percepção dos filhos sobre o casamento de seus pais.

Na segunda etapa do estudo, foi realizada uma pesquisa qualitativa, utilizando uma entrevista semi-estruturada, para avaliar a concepção, as expectativas e os ideais sobre casamento dos jovens, com o objetivo de explorar as possíveis relações existentes entre a percepção dos filhos sobre o casamento de seus pais e aquilo que o laço conjugal representava para eles.

Alguns trabalhos já foram publicados com dados parciais desta investigação. Dentre eles, Féres-Carneiro, Seixas e Ziviani (2006) e Féres-Carneiro, Ziviani e Magalhães (2007). Dentre outros resultados, constatou-se que quando os jovens incluíram o casamento em seus projetos de vida, afirmaram desejar construir projetos bem distintos das percepções que tiveram da conjugalidade de seus pais, mesmo quando essa foi avaliada como muito satisfatória. Na maioria dos casos em que os jovens apresentaram um discurso de franca recusa à percepção da influência da conjugalidade dos pais sobre o lugar que essa ocupa em seus projetos de vida, tais pais eram casados e sua conjugalidade foi avaliada como muito insatisfatória. Considerou-se que esse resultado evidencia o quanto o não enfrentamento pelos pais de seus conflitos conjugais, e a manutenção de uma relação conjugal insatisfatória se expressam no processo de identificação e de diferenciação dos filhos e, conseqüentemente, na possibilidade de elaborar projetos de vida mais autônomos.

O lugar que o casamento ocupa nos projetos de vida parece estar relacionado com o modo como os jovens entrevistados se apropriaram de sua herança familiar e com o discernimento sobre os aspectos da conjugalidade dos pais que os influenciaram. Em trabalho anterior (Magalhães \& Féres-Carneiro, 2003), ressaltou-se que o desvelamento dos elos da cadeia geracional e das posições ocupadas pelos familiares uns em relação aos outros, posições essas cambiáveis e múltiplas, permite ao sujeito não somente a apropriação de seu lugar na transmissão psíquica geracional, mas também a relativização de sua missão. A possibilidade de estruturar um lugar para a conjugalidade no psiquismo depende, sobretudo, de condições de diferenciação promovidas na família.

Ainda estamos elaborando trabalhos a serem publicados a partir dos dados obtidos nesta investigação, que articulou métodos quantitativos e qualitativos, em busca de aprofundar questões que envolviam o lugar que o casamento ocupa hoje no projeto dos jovens solteiros.

Estamos realizando também o estudo de validação do "Questionário sobre a conjugalidade dos pais", construído para o desenvolvimento da investigação que acaba de ser concluída. O referido questionário já foi aplicado a 1650 sujeitos, com idades entre 18 e 29 anos, de diferentes segmentos sociais. Deste modo, após sua validação, poderemos contar com mais um método de avaliação para ser utilizado em pesquisas sobre família, com enfoque no casal parental e no casal conjugal.

O Projeto de pesquisa que foi aprovado pelo CNPq, para o período de março de 2008 a fevereiro de 2011, intitula-se "Conjugalidades contemporâneas: Um estudo sobre os múltiplos arranjos conjugais da atualidade", e tem como objetivo mapear conceitualmente os diversos arranjos conjugais contemporâneos, identificando as variáveis que os sujeitos envolvidos nestes laços indicam como definidoras de tais arranjos. Será utilizada uma metodologia qualitativa, centrada em entrevista semi-estruturada. A amostra de conveniência será constituída de 100 sujeitos, das camadas médias da população carioca, com idades entre 20 e 50 anos, sendo 50 homens e 50 mulheres, distribuídos em grupos de 4 sujeitos heterossexuais e 2 sujeitos homossexuais, nos seguintes arranjos conjugais: "ficar com", namoro, noivado, coabitação, união estável, casamento civil, recasamento, casamento em casas separadas e "poliamor". O "poliamor" é definido como uma nova modalidade de relacionamento amoroso, específica da não-monogamia, surgida na década de 90, sem ligação com uma identidade sexual particular, na qual se acredita ser possível e aceitável amar muitas pessoas e manter múltiplos relacionamentos íntimos, se houver honestidade quanto a eles e se não for pensada, necessariamente, em termos de relacionamentos sexuais (Barker, 2005). Adotaremos, no desenvolvimento desta investigação, uma ótica multidisciplinar, articulando os saberes da sociologia, da antropologia, da psicologia social e da psicanálise de família e casal.

Na clínica de família e casal, tenho me deparado com todos os arranjos acima referidos, com exceção, até o momento, do "poliamor". Como nas outras investigações relatadas, mesmo aquelas que não foram realizadas no setting clínico, na maioria dos casos, minhas questões de pesquisa surgiram na prática clínica. Acredito que esta investigação, como as demais que relatei, trará subsídios importantes para a prática das psicoterapias individual, de família e de casal, para as quais as questões relacionadas à conjugalidade e às suas múltiplas formas estão cada vez mais presentes. 
Assim, minha proposta de construção de articulações, como a de outros autores, não desconsidera a importância da consistência entre teoria e prática, e a coerência com uma determinada posição epistemológica. Entretanto, dentro de uma mesma posição epistemológica, incontáveis modelos de atendimento são possíveis. Como ressalta Maturana (1990), há diversos modos de fazer terapia e estes modos distintos têm a ver com as distintas características dos terapeutas. Para ele, haverá tantas propostas terapêuticas quantos forem os terapeutas.

No início da minha fala de hoje, ressaltei minhas características de negociadora, articuladora, conciliadora de posições, "radical de centro", como diria, de modo carinhoso, meu marido. Não é por acaso que exerço há 36 anos as funções de docente-pesquisadora e de psicóloga clínica, concebendo tais funções como indissociáveis. Não é por acaso que, no exercício da clínica, escolhi ser terapeuta de família e casal, e que, neste lugar, proponho (como vários outros autores de grande projeção na área), a articulação das abordagens sistêmicas e psicanalíticas. O mais importante é que o terapeuta faça uma escolha ética, lançando mão de todas as possibilidades teórico-técnicas ao seu alcance, para intervir de modo a alcançar o melhor benefício terapêutico para o seu paciente.

E é neste movimento dialético que se dá da clínica para a pesquisa e da pesquisa que, de volta para clínica, pode modificá-la, que pretendo continuar construindo múltiplas articulações: articulações entre diferentes saberes, articulações entre diferentes abordagens teórico-técnicas, articulações entre diferentes sujeitos que se constroem e se reconstroem na intersubjetividade, buscando ver, nas diferenças, muito mais possibilidades de as mesmas se complementarem do que de se excluírem mutuamente.

\section{Referências}

Barker, M. (2005). This is my partner, and this is my partner's partner: Constructing a polyamorous identity in a monogamous world. Journal of Constructivist Psychology, 18, 75-88.

Féres-Carneiro, T. (1975). Entrevista Familiar Estruturada: Um novo método clínico de avaliação das relações familiares. Dissertação de Mestrado não-publicada, Curso de PósGradução em Psicologia Clínica, Pontifícia Universidade Católica do Rio de Janeiro, RJ.

Féres-Carneiro, T. (1980). Psicoterapia de casal e suas repercussões no comportamento dos filhos. Arquivos Brasileiros de Psicologia, 32(4), 51-60.

Féres-Carneiro, T. (1981). Entrevista familiar estruturada: Sua consistência, validade e aplicabilidade em Psicologia Clíni$c a$. Tese de Doutorado não-publicada, Curso de Pós-Gradução em Psicologia Clínica, Pontifícia Universidade Católica de São Paulo, SP.

Féres-Carneiro, T. (1983). Família: Diagnóstico e terapia. Rio de Janeiro, RJ: Zahar.

Féres-Carneiro, T. (1987). Aliança e sexualidade no casamento e no recasamento contemporâneo. Psicologia: Teoria e Pesquisa, 3(3), 250-261.

Féres-Carneiro, T. (1993). Academia e profissão em Psicologia Clínica: Da relação possível à relação desejável. Psicologia: Reflexão e Crítica, 6(1/2), 103-105.
Féres-Caneiro, T. (1995). Terapia de casal: Ruptura ou manutenção do casamento? Temas em Psicologia, 2, 37-52.

Féres-Carneiro, T. (1996). Terapia familiar: Das divergências às possibilidades de articulação dos diferentes enfoques. Psicologia: Ciência e Profissão, 16, 38-42.

Féres-Carneiro, T. (1997). Escolha amorosa e interação conjugal na heterossexualidade e na homossexualidade. Psicologia: Reflexão e Crítica, 10(2), 351-368.

Féres-Carneiro, T. (1999). Conjugalidade: Um estudo sobre as diferentes dimensões da relação amorosa heterossexual e homossexual. In T. Féres-Carneiro, Casal e família: Entre a tradição e a transformação (pp. 96-117). Rio de Janeiro, RJ: Nau.

Féres-Carneiro, T. (2001). Casamento contemporâneo: Construção da identidade conjugal. In T. Féres-Carneiro, Casamento e família: Do social à clínica (pp. 67-80). Rio de Janeiro, RJ: Nau.

Féres-Carneiro, T. (2003a). Separação: O doloroso processo de dissolução da conjugalidade. Estudos de Psicologia (Natal), 8(3), 367-374.

Féres-Carneiro, T. (2003b). Construção e dissolução do laço conjugal na terapia de casal. In T. Féres-Carneiro, Família e casal: Arranjos e demandas contemporâneas (pp. 201-214). Rio de Janeiro, RJ: Editora da Pontifícia Universidade Católica do Rio de Janeiro.

Féres-Carneiro, T. (2006). Entrevista Familiar Estruturada: Um método clínico de avaliação das relações. São Paulo, SP: Casa do Psicólogo.

Féres-Carneiro, T., Seixas, A., \& Ziviani, C. (2006). Conygalidad de los padres y proyectos de vida de los hijos frente al matrimonio. Cultura y Educación, 18(1), 95-108.

Féres-Carneiro, T., Ziviani, C., \& Magalhães, A. S. (2007). Questionário sobre a conjugalidade dos pais como instrumento de avaliação. In T. Féres-Carneiro, Família e casal: Saúde, trabalho e modos de vinculação (pp. 251-268). São Paulo, SP: Casa do Psicólogo.

Fry, P., \& MacRae, E. (1981). O que é a homossexualidade? São Paulo, SP: Brasiliense.

Gomes, W. B., \& Hutz, C. (1987). A prática clínica e o trabalho acadêmico: Uma entrevista com a psicóloga Terezinha Féres Carneiro. Psicologia: Reflexão e Crítica, 2(1/2), 73-78.

Heilborn, M. L. (1993). Vivendo a dois: Arranjos conjugais em comparação. Revista Brasileira de Estudos da População, 10(1/2), 25-40.

Jablonski, B. (1998). Até que a vida nos separe: A crise do casamento contemporâneo. Rio de Janeiro, RJ: Agir.

Lemaire, J. (1984). Le couple, sa vie, sa mort. Paris: Payot.

Magalhães, A. S. (1993). Individualismo e conjugalidade: Um estudo sobre o casamento contemporâneo. Dissertação de Mestrado não-publicada, Curso de Pós-Gradução em Psicologia Clínica, Pontifícia Universidade Católica do Rio de Janeiro, RJ.

Magalhães, A. S., \& Féres-Carneiro, T. (2003). A conjugalidade na série identificatória: Experiência amorosa e recriação do eu. Pulsional Revista de Psicanálise, 16(176), 41-50.

Maturana, H. (1990). Biología de la cognición y epistemología. Temuco, Chile: Universidad de la Frontera.

Nicollò, A. M. (1988). Soigner à l'intérieur de l'autre: notes sur la dynamique entre l'individu et la famille. Rome: Mimeo.

Piccinini, C. A. (1996). Sobre o relacionamento entre pesquisador e profissional em Psicologia [Special issue]. Coletâneas da ANPEPP, 1(8), 31-40.

Recebido: 25/03/2008

$I^{a}$ revisão: $20 / 08 / 2008$ Aceite final: $26 / 08 / 2008$ 